\title{
Effects of a Novel Selective EP2 Receptor Agonist, Omidenepag Isopropyl, on Aqueous Humor Dynamics in Laser-Induced Ocular Hypertensive Monkeys
}

\author{
Masahiro Fuwa,,, Carol B. Toris, ${ }^{2,3,{ }^{*}}$ Shan Fan,2 Takazumi Taniguchi,, Masaki Ichikawa, \\ Noriko Odani-Kawabata, Ryo Iwamura, Kenji Yoneda, Takeshi Matsugi, \\ Naveed K. Shams, ${ }^{4,6}$ and Jin-Zhong Zhang ${ }^{1,6}$
}

\begin{abstract}
Purpose: To investigate the mechanism of the intraocular pressure (IOP)-lowering effect of a novel selective prostaglandin E2 receptor 2 (EP2) receptor agonist, omidenepag isopropyl (OMDI).

Methods: The effect of OMDI on IOP and aqueous humor dynamics was evaluated in cynomolgus monkeys with unilateral laser-induced ocular hypertension. In a crossover manner, the hypertensive eye of each monkey was dosed once daily with $20 \mu \mathrm{L}$ of either $0.002 \%$ OMDI or vehicle. On day 7 of dosing, IOP was measured by pneumatonometry, aqueous humor flow and outflow facility were evaluated by fluorophotometry, and uveoscleral outflow was calculated mathematically. Treatments were compared by paired $t$-tests.

Results: OMDI at $0.002 \%$ significantly lowered IOP by $27 \%, 35 \%$, and $44 \%$ at $0.5,1.5$, and $4 \mathrm{~h}$ after the last dosing, respectively. There was no difference in aqueous humor flow between vehicle and OMDI treatments. When comparing OMDI to the vehicle treatment, outflow facility and uveoscleral outflow were significantly $(P<0.05)$ increased by $71 \%$ and $176 \%$, respectively.

Conclusions: OMDI, a novel IOP-lowering compound, reduced IOP by increasing outflow facility and uveoscleral outflow in nonhuman primates.
\end{abstract}

Keywords: glaucoma, aqueous humor dynamics, EP2 receptor, intraocular pressure

\section{Introduction}

G LAUCOMA, A NEURODEGENERATIVE disease characterized by selective loss of retinal ganglion cells followed by visual field defects, is the leading cause of irreversible blindness worldwide. ${ }^{1-4}$ Elevated intraocular pressure (IOP) is a major factor for glaucoma, and IOP reduction remains the main goal of current glaucoma therapy. ${ }^{3,5-7}$ Glaucoma patients are treated initially with pharmacological monotherapy, such as prostaglandin $\mathrm{F}$ (FP) receptor agonists (FP agonists) or beta-adrenergic receptor blockers (beta blockers). However, $\sim 30 \%$ of glaucoma patients require adjunctive therapy within 1 year, and $>40 \%$ of glaucoma patients rely on adjunctive therapy to control their IOP; hence, 2 or more drugs are often added to the treatment regimen. ${ }^{8-12}$ From a safety viewpoint, beta blockers may cause serious systemic side effects in the cardiovascular and respiratory systems, ${ }^{13-15}$ and FP agonists can stimulate pigmentation in periocular skin and iris, deepen the upper eyelid sulcus, and cause abnormal elongation of eyelashes. ${ }^{16-18}$ As such, there remains a need for more potent and safer IOP-lowering drugs with novel mechanisms of action.

The prostaglandin E2 receptor 2 (EP2) receptor could be an alternative target for IOP regulation. It is a G-protein coupled receptor found in several ocular tissues, including nonpigmented ciliary epithelium, trabecular meshwork (TM),

\footnotetext{
${ }^{1}$ R\&D Division, Santen Pharmaceutical Co., Ltd., Nara, Japan.

${ }^{2}$ Department of Ophthalmology, Nebraska Medical Center, University of Nebraska Medical Center, Omaha, Nebraska.

${ }^{3}$ Department of Ophthalmology, Case Western Reserve University, Cleveland, Ohio.

${ }_{5}^{4}$ R\&D Division, Santen Pharmaceutical Co., Ltd., Osaka, Japan.

${ }^{5}$ Pharmaceuticals Research Laboratory, Pharmaceutical Division, Ube Industries, Ltd., Yamaguchi, Japan.

${ }^{6}$ R\&D Division, Santen, Inc., Emeryville, California.

*These authors contributed equally to this work.
}

(C) Masahiro Fuwa et al. 2018; Published by Mary Ann Liebert, Inc. This Open Access article is distributed under the terms of the Creative Commons Attribution Noncommercial License (http://creativecommons.org/licenses/by-nc/4.0/) which permits any noncommercial use, distribution, and reproduction in any medium, provided the original author(s) and the source are cited. 
and ciliary muscle $(\mathrm{CM}),{ }^{19,20}$ tissues that are associated with aqueous humor dynamics (AHD). Prostaglandin $\mathrm{E}_{2}\left(\mathrm{PGE}_{2}\right)$ is an endogenous ligand for EP receptors; these receptors have 4 subtypes as follows: EP1, EP2, EP3, and EP4. ${ }^{21,22} \mathrm{Al}-$ though $\mathrm{PGE}_{2}$ has a potent IOP-lowering effect, it is associated with some adverse effects. ${ }^{23}$ Several promising agonists to EP2 receptor have shown IOP-lowering effects with fewer adverse effects than those of $\mathrm{PGE}_{2}{ }^{24-26} \mathrm{Omi}-$ denepag isopropyl (OMDI) is one such compound. ${ }^{27}$ After topical instillation, OMDI is converted to omidenepag (OMD) during corneal penetration. ${ }^{27}$ OMD is a highly selective EP2 receptor agonist $\left(\mathrm{K}_{\mathrm{i}}=3.6 \mathrm{nM}\right.$ in binding affinity, and $\mathrm{EC}_{50}=8.3 \mathrm{nM}$ in agonistic activity) with a nonprostaglandin structure (Fig. 1). ${ }^{27}$ The IOP-lowering effect of OMDI has been demonstrated in several animal models, including rabbits, dogs, and monkeys, and in patients with primary open-angle glaucoma or ocular hypertension, ${ }^{27,28}$ which suggests that OMDI has potential for future glaucoma treatment. The current study tests the hypothesis that OMDI lowers IOP by improving outflow through both aqueous humor drainage pathways, a mechanism somewhat different from other EP2 agonists. ${ }^{29,30}$

In this study, we investigated the mechanism of the IOPlowering effect of OMDI by examining AHD in ocular hypertensive monkeys.

\section{Methods}

\section{Drugs}

OMDI was synthesized by Ube Industries, Ltd. (Yamaguchi, Japan) (Fig. 1). An ophthalmic solution of $0.002 \%$ OMDI and its vehicle were formulated by Santen Pharmaceutical Co., Ltd. (Osaka, Japan). The vehicle contained citrate buffer, polyoxyl 35 castor oil, edetate disodium, glycerin, $\mathrm{pH}$ adjuster, water, and benzalkonium chloride as a preservative. Acetazolamide was purchased from Ben Venue Laboratories, Inc. (Bedford, $\mathrm{OH}$ ).

\section{Animals}

Fifteen female cynomolgus monkeys (Charles River Laboratories, Inc., Wilmington, MA or Covance, Inc., Princeton, $\mathrm{NJ}$ ) had laser treatments to the TM of the left eye to create unilateral laser-induced ocular hypertension. ${ }^{31}$ The lasering had been done between 5 and 13 years before the study. Fifty to 100 argon laser photocoagulation burns, with a spot size of 50 microns, a power of $1,000 \mathrm{~mW}$, and an exposure time of $0.5 \mathrm{~s}$ were applied to the midportion of the
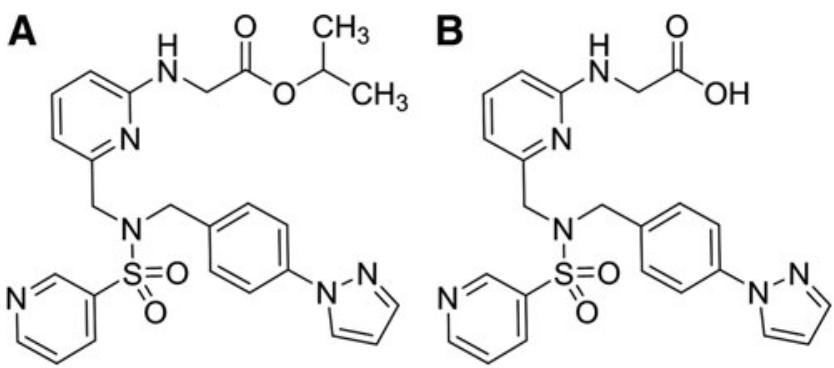

FIG. 1. Chemical structures of OMDI and OMD. (A) OMDI, (B) OMD. OMDI, omidenepag isopropyl; OMD, omidenepag.
TM for 340 degrees. The animals were between 9 and 18 years of age and weighing $3.2-6.6 \mathrm{~kg}$ when they were used in the study. Animals were housed in a temperature and humidity controlled room with lights on for $12 \mathrm{~h}$ per day starting at 7:00 am. All animal care and experimental procedures were performed in accordance with the ARVO Statement for the Use of Animals in Ophthalmic and Vision Research and were approved and monitored by the Animal Care and Use Committee at the University of Nebraska Medical Center.

\section{AHD study}

The AHD methods were similar to those described previously. ${ }^{32,33}$ The study was performed according to the schedule described in Fig. 2. Briefly, the study was an investigator-masked crossover design of OMDI or vehicle treatment to the hypertensive eye of each animal. The effects of OMDI on AHD were determined by comparing OMDI treatment data with vehicle treatment data and with baseline measurement of IOP (before dosing). The 2 measurement days were separated in time by at least 2 weeks to allow recovery from anesthesia and for washout of drug effects. Twenty microliters of either $0.002 \%$ OMDI ophthalmic solution or vehicle were applied between 8:00 and 9:00 am to hypertensive eyes once daily for 7 days. Dosing period and concentration of OMDI ophthalmic solution were determined on the basis of our previous animal ${ }^{27}$ and clinical data. ${ }^{28,34}$ On day $7, \sim 4 \mathrm{~h}$ before measurements commenced, $10 \%$ fluorescein solution was applied to the cornea as 3 to 4 topical drops and then sedation was induced by intramuscular administration of ketamine $\mathrm{HCl}(15 \mathrm{mg} / \mathrm{kg})$. A final dose of $0.002 \%$ OMDI ophthalmic solution or vehicle was applied topically to the eye at around 9:00 am.

The cornea was anesthetized with topical proparacaine $\mathrm{HCl} 0.5 \%$, and IOP was measured using a pneumatonometer (Model 30; Reichert, Inc., Depew, NY). Corneal thickness and anterior chamber depth were measured by slit-lamp pachymetry, cornea diameter was measured with calipers, and cornea and anterior chamber volumes were calculated from the measured values of cornea diameter, cornea thickness, and anterior chamber depth. ${ }^{35}$ Beginning at $\sim 9: 30 \mathrm{am}$, the fluorescence intensities of the cornea and anterior chamber were measured using a scanning ocular fluorophotometer (Fluorotron Master; OcuMetrics, Inc., Mountain View, CA). Scans were repeated thrice at 45-min intervals for a total of 4 sets of scans. The slopes of the cornea and anterior chamber fluorescein decay curves and the anterior chamber volume were used in the determination of aqueous flow $\left(F_{\mathrm{a}} ; \mu \mathrm{L} / \mathrm{min}\right)$. The numerous formulas have been reported in detail elsewhere. ${ }^{36,37}$

Immediately after the fourth set of scans, IOP was measured $\left(\mathrm{IOP}_{1} ; \mathrm{mmHg}\right)$, and acetazolamide $(20 \mathrm{mg} / \mathrm{kg})$ was given by intravenous injection. This carbonic anhydrase inhibitor was used as a tool to reduce IOP and $F_{\text {a }}$ and enable calculation of outflow facility. At 1.0, 1.75, and $2.5 \mathrm{~h}$ later, fluorophotometric scans, $F_{\mathrm{a}}$ calculations, and IOP measurements were repeated. At each of these 3 postacetazolamide periods, fluorophotometric outflow facility $\left(C_{\mathrm{fl}} ; \mu \mathrm{L} / \mathrm{min} / \mathrm{mmHg}\right)$ was calculated as the ratio of the change in $F_{\mathrm{a}}$ to the change in IOP from the acetazolamide administration. ${ }^{38}$ If there was $<0.1 \mu \mathrm{L}$ decrease in $F_{\mathrm{a}}$ or $<0.5 \mathrm{mmHg}$ decrease in IOP at a postacetazolamide period, $C_{\mathrm{fl}}$ was not calculated for that period. The reported 


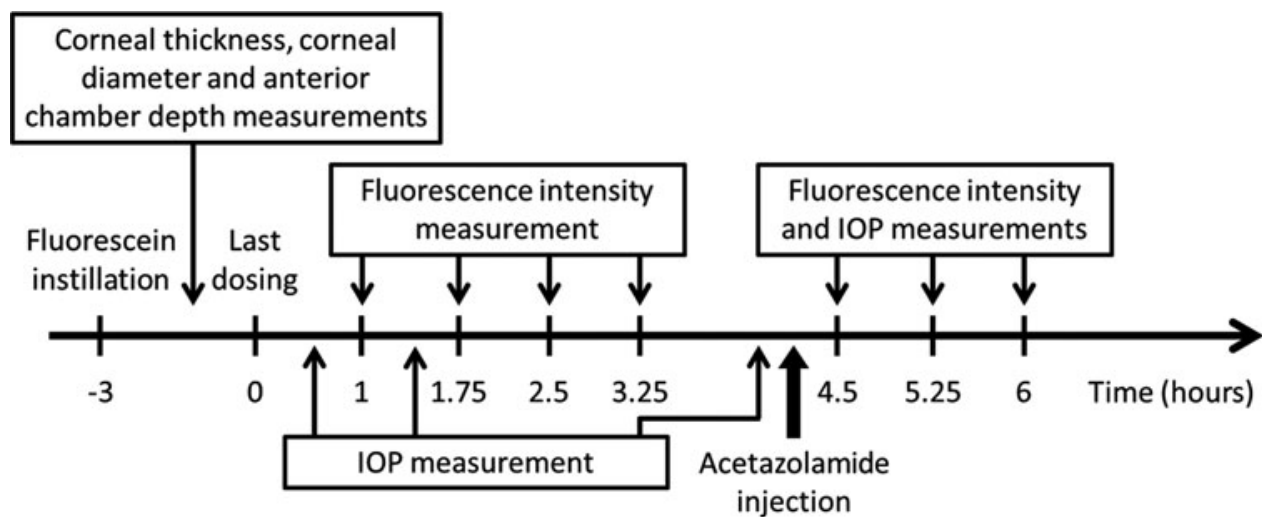

FIG. 2. Timeline of the study measurements and dosing. Fluorescein instillation and the last dosing of vehicle or $0.002 \%$ OMDI were performed at $\sim 6: 00$ and 9:00 am, respectively. IOP and fluorescence intensity were measured on the basis of the above timeline for the evaluation of AHD. AHD, aqueous humor dynamics; IOP, intraocular pressure.
$C_{\mathrm{fl}}$ is the average of 2 to 3 calculated values. If only one or no acceptable postacetazolamide $C_{\mathrm{fl}}$ value was calculated, then a mean $C_{\mathrm{fl}}$ was not recorded for that eye.

Episcleral venous pressure $\left(P_{\mathrm{ev}} ; \mathrm{mmHg}\right)$ could not be measured using the noninvasive technique of venomanometry in the monkeys because of their heavily pigmented conjunctiva that prevented visualization of the vessels. $P_{\mathrm{ev}}$ also could not be measured by direct cannulation because of its invasive nature. Instead, estimates were made on the basis of a prior publication $^{39}$ that used direct cannulation techniques in nonhuman primates. Based on that information, we chose the value of $14 \mathrm{mmHg}$ as the estimated $P_{\mathrm{ev}}$ value in this study.

Uveoscleral outflow $\left(F_{\text {us }} ; \mu \mathrm{L} / \mathrm{min}\right)$ was calculated for each animal using the modified Goldmann equation, $F_{\mathrm{us}}=F_{\mathrm{a}}$ $-C_{\mathrm{fl}}\left(\mathrm{IOP}_{1}-14\right)$. If any of the variables in the Goldmann equation were missing, then $F_{\text {us }}$ could not be calculated for that eye.

IOPs and aqueous flow values were collected in 15 animals. Mean $C_{\mathrm{fl}}$ was reported in 8 animals due to the strict criteria for the $C_{\mathrm{fl}}$ calculation. Uveoscleral outflow was calculated in the same 8 animals.

\section{Statistical analyses}

IOP $(\mathrm{mmHg}), F_{\mathrm{a}}(\mu \mathrm{L} / \mathrm{min}), C_{\mathrm{fl}}(\mu \mathrm{L} / \mathrm{min} / \mathrm{mmHg})$, and $F_{\text {us }}$ $(\mu \mathrm{L} / \mathrm{min})$ were analyzed. Parameters were compared between the vehicle and $0.002 \%$ OMDI-treated groups using the 2-tailed paired $t$-test. Differences were considered statistically significant if $P<0.05$.

\section{Results}

At the beginning of the study, IOP in the laser-treated eye was found to be significantly higher than that in the fellow eye of each monkey (data not shown). No statistically significant differences in baseline IOP values were observed on days of vehicle and OMDI treatments. OMDI at $0.002 \%$ significantly lowered IOP at $0.5,1.5$, and $4 \mathrm{~h}$ after the last dosing by $27 \%, 35 \%$, and $44 \%$ reduction compared with the vehicle treatments, respectively (Fig. 3).

When comparing $0.002 \%$ OMDI with vehicle treatments, there was no difference in aqueous humor production (Fig. 4A), an increase in outflow facility from $0.11 \pm 0.03 \mu \mathrm{L} /$ $\mathrm{min} / \mathrm{mmHg}$ to $0.18 \pm 0.04 \mu \mathrm{L} / \mathrm{min} / \mathrm{mmHg}(71 \%$ increase; $P=0.028)$ (Fig. 4B), and an increase in uveoscleral outflow from $1.07 \pm 0.50 \mu \mathrm{L} / \mathrm{min}$ to $2.94 \pm 0.55 \mu \mathrm{L} / \mathrm{min}(176 \%$ increase; $P=0.033$ ), respectively (Fig. 4C).

\section{Discussion}

OMDI is a novel selective EP2 receptor agonist with a nonprostaglandin structure (Fig. 1) under development for the treatment of glaucoma as an IOP-lowering drug. ${ }^{27}$ Based on the efficacy results of our previous animal ${ }^{27}$ and clinical studies, we administered $0.002 \%$ OMDI for 7 days, which was expected to show a greater IOP-lowering effect compared with a single dose in monkeys. With this dosing regimen, OMDI at $0.002 \%$ significantly lowered IOP by $\sim 19,23$, and $26 \mathrm{mmHg}$ compared to the baseline at 0.5 , 1.5 , and $4 \mathrm{~h}$ after the last dosing, respectively (Fig. 3), and increased outflow facility and uveoscleral outflow (Fig. 4). Previously, we evaluated the IOP-lowering effects of one of the FP agonists, travoprost $\left(0.004 \%\right.$; TRAVATAN $\left.{ }^{\circledR}\right)$, showing the reduction of IOP by $\sim 10 \mathrm{mmHg}$ in laserinduced ocular hypertensive monkeys. ${ }^{40}$ Recently, we also indicated that OMDI at $0.01 \%$ and latanoprost $(0.005 \%$; Xalatan $^{\circledR}$ ) showed the maximal IOP reductions of 19.9 and $9.7 \mathrm{mmHg}$, respectively, in laser-induced ocular hypertensive monkeys. ${ }^{27}$ These findings suggest that at least at certain dosing regimen and measurement times, the IOPlowering effects of OMDI are greater than those of FP agonists in laser-induced ocular hypertensive monkeys. We also reported that OMDI dose dependently lowered IOP

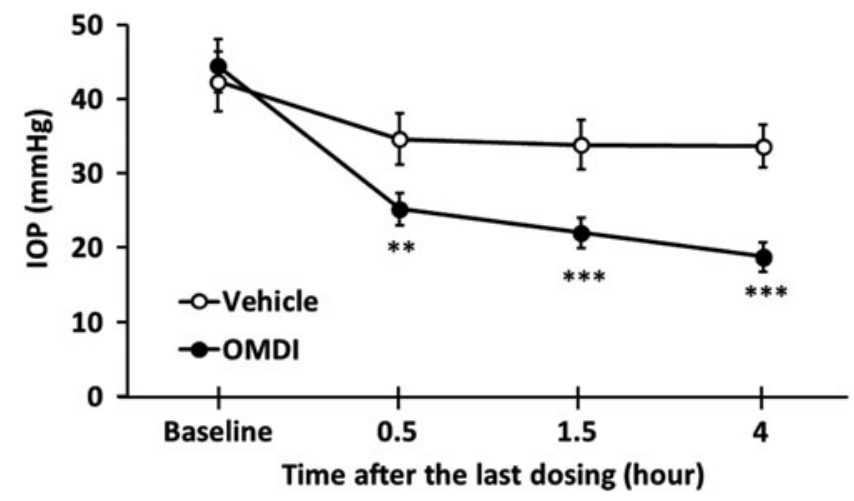

FIG. 3. Effects of OMDI ophthalmic solution on IOP in ocular hypertensive monkey eyes. IOPs were measured before the acetazolamide injection. IOPs of vehicle or $0.002 \%$ OMDI are represented as the mean \pm SEM of 15 eyes. $* * P<0.01, * * * P<0.001$ compared with vehicle by paired $t$-test. 


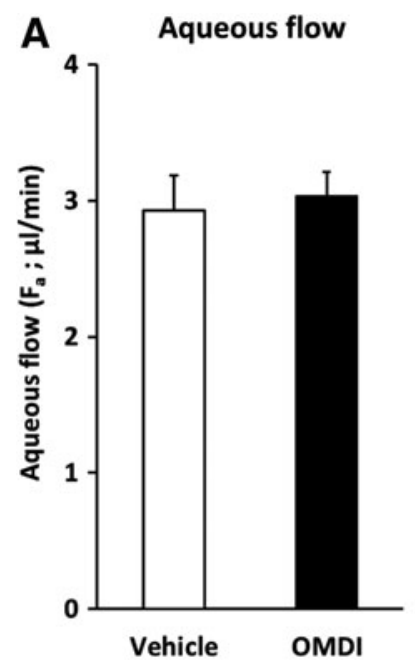

FIG. 4. Effects of OMDI ophthalmic solution on AHD in ocular hypertensive monkey eyes. AHD parameters following treatment with vehicle or $0.002 \%$ OMDI are represented as mean \pm SEM of 15 eyes for aqueous flow (A) and 8 eyes for both outflow facility (B) and uveoscleral outflow (C), respectively. $* P<0.05$ compared with vehicle by paired $t$-test.
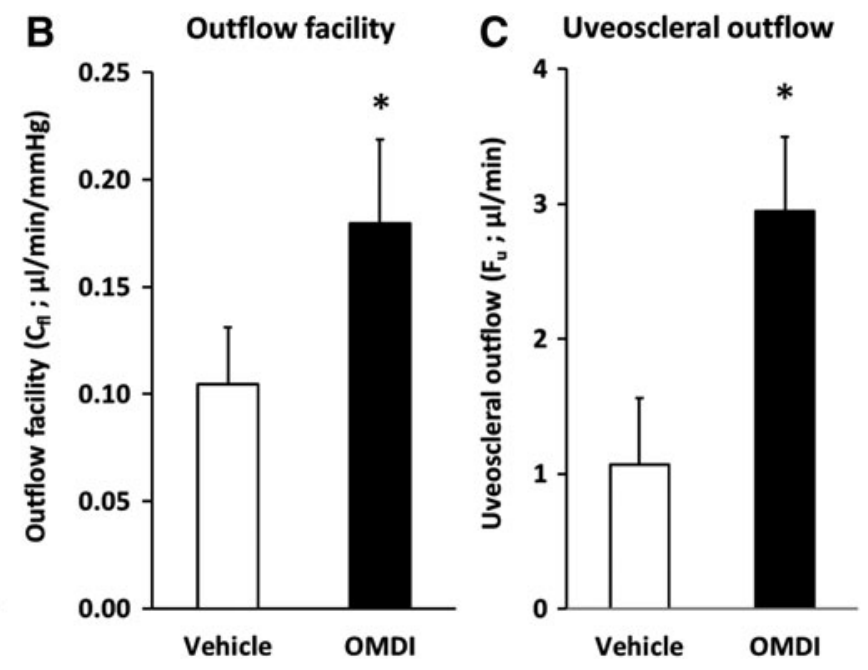

at doses of $0.0001 \%, 0.001 \%$, and $0.01 \%$ in ocular normotensive monkeys with maximal IOP reductions of 2.4, 7.6 , and $13.3 \mathrm{mmHg}$, respectively, and also that OMDI reached the peak of IOP-lowering effect during 4 to $8 \mathrm{~h}$ after the instillation. ${ }^{27}$ In addition, the significant decreases in IOP for $0.001 \%$ and $0.01 \%$ OMDI at time 0 on day 7 of dosing (trough) suggested that its efficacy lasted more than 24 h. $^{27}$

The outflow facility in this study was accessed by the fluorophotometric method. ${ }^{35}$ This method directly measures changes in aqueous flow and IOP from the acetazolamide treatment. It does not apply a weight to the eye, as is done with tonography, and thus avoids the confounding factors of ocular rigidity and pseudofacility. However, it cannot separate facility of trabecular outflow from facility of uveoscleral outflow. The facility of uveoscleral outflow is small in primates ${ }^{41-43}$; hence, it is assumed that the changes in outflow facility measured by the fluorophotometry method mainly reflect changes in trabecular outflow facility. ${ }^{44}$ In support of this assumption, a previous study of cats found that, when measured by direct invasive methods, uveoscleral outflow and total outflow facility were increased yet uveoscleral outflow facility was unchanged following treatment with prostaglandin $\mathrm{A}_{2} .{ }^{45}$ The conclusion could be made that prostaglandin $\mathrm{A}_{2}$ improved outflow facility through the TM. Similarly, we could conclude with some confidence that OMDI increases trabecular outflow facility.

Our data demonstrate that OMDI has a dual mechanism of action of improving drainage through both outflow pathways. Outflow facility is low, and uveoscleral outflow rate is slow in patients with elevated IOP, ${ }^{4,46}$ which means that OMDI targets the 2 areas of pathology in the anterior segment of glaucomatous eyes. OMDI's mechanism of action is somewhat different from other IOP lowering drugs making it potentially synergistic or additive when combined with existing IOP-lowering drugs. FP agonists lower IOP predominantly by increasing uveoscleral outflow and to a lesser extent trabecular outflow facility. ${ }^{44}$ Beta blockers inhibit aqueous humor production. ${ }^{47}$ The alpha 2 receptor agonist, brimonidine, also inhibits aqueous humor production but only when dosed acutely. ${ }^{48}$ When dosed for multiple days, it increases uveoscleral outflow. ${ }^{48}$ Rho kinase inhibitors mainly improve outflow facility, ${ }^{33,49}$ although an effect on $P_{\mathrm{ev}}{ }^{50}$ and uveoscleral outflow ${ }^{33}$ also contribute to its IOP-lowering effect. We previously confirmed the adjunctive IOP-lowering effect of OMDI in animal models. ${ }^{51}$ Furthermore, because of its dual mechanism of action, OMDI might be effective in patients who are less or nonresponsive to FP agonists.

EP2 receptor expression has been confirmed in the CM (part of the uveoscleral outflow pathway) and TM (part of the trabecular outflow pathway). ${ }^{19}$ Stimulation of EP2 receptors leads to an increase in intracellular cAMP, ${ }^{52}$ which results in relaxation of smooth muscle. ${ }^{53} \mathrm{EP} 2$ agonists relax both tissues and cells in the CM and TM. ${ }^{54-57}$ Therefore, it is thought that this compound improves uveoscleral outflow and trabecular outflow facility. Nilsson et al. ${ }^{30}$ found that butaprost, another EP2 agonist, increased uveoscleral outflow but not outflow facility. However, after dosing for a year, there was enlargement of intercellular spaces and decrease in collagen-like extracellular matrix in the TM and Schlemm's canal suggesting an improvement in outflow facility with long-term dosing. Since EP2 receptor stimulation is involved in induction of matrix metalloproteinase (MMP) protein and activation of MMPs, ${ }^{58,59}$ the structural changes in both TM and CM tissues are probably caused by changes in the extracellular matrix. Based on these findings and our data in the current study (Fig. 4), the mechanism of the IOP-lowering effect of OMDI potentially involves increased trabecular outflow facility through expansion of the intercellular spaces, reduction of extracellular matrices and relaxation of TM, and increased uveoscleral outflow through relaxation of the $\mathrm{CM}$.

Elevated IOP in glaucoma patients is caused mainly by a decrease in trabecular outflow facility. ${ }^{4,46}$ The animal model used in this study had ocular hypertension as a result of lasering the TM that caused tissue scarring and increased resistance through the outflow pathway. This model is similar to human glaucoma in that it has reduced outflow facility, nerve fiber layer defects, and progressive enlargement of the cup-to-disc ratio. ${ }^{60,61}$ An important distinction of note is that the monkey model is an injury model unlike human primary open-angle glaucoma. Nevertheless, the animal does respond to drugs that affect the TM and provides results that extrapolate to glaucoma patients. 
In conclusion, this study in ocular hypertensive monkeys finds that OMDI lowers IOP by increasing both trabecular outflow facility and uveoscleral outflow. This novel selective EP2 receptor agonist could be a new option for the treatment of glaucoma.

\section{Acknowledgments}

The authors thank Lisa Reid and Toni Goeser for their excellent technical assistance in the animal experiments; Naoko Yamashita, Miki Takahashi, and Dr. Yasuko Yamamoto for their support during analysis of the experimental data; Masafumi Mieda, Dr. Takahiro Akaishi, and Yuki Asai for their support preparing the protocol; and Yoko Endo for preparation of testing drugs. Supported by Research to Prevent Blindness (University of Nebraska Medical Center and Case Western Reserve University) and Santen Pharmaceutical Co., Ltd.

\section{Author Disclosure Statement}

M.F., T.T., M.I., N.O.K., and T.M. are employees at Santen Pharmaceutical Co., Ltd., and N.K.S. and J.Z.Z. are employees at Santen Inc. R.I. and K.Y. are employees at Ube Industries, Ltd. During the past 2 years, C.B.T. received research support from companies developing IOP-lowering drugs, including Santen Pharmaceutical Co., Ltd., Novartis International AG, Nicox S.A., and F. Hoffmann-La Roche Ltd.

\section{References}

1. Quigley, H.A., and Broman, A.T. The number of people with glaucoma worldwide in 2010 and 2020. Br. J. Ophthalmol. 90:262-267, 2006.

2. Weinreb, R. Glaucoma neuroprotection: what is it? Why is it needed? Can. J. Ophthalmol. 42:396-398, 2007.

3. Quigley, H.A. Glaucoma. Lancet. 377:1367-1377, 2011.

4. Jonas, J.B., Aung, T., Bourne, R.R., Bron, A.M., Ritch, R., and Panda-Jonas, S. Glaucoma. Lancet. 390:2183-2193, 2017.

5. Coleman, A.L., and Miglior, S. Risk factors for glaucoma onset and progression. Surv. Ophthalmol. 53 Suppl1:S3-S10, 2008.

6. Collaborative Normal-Tension Glaucoma Study Group. Comparison of glaucomatous progression between untreated patients with normal-tension glaucoma and patients with therapeutically reduced intraocular pressures. Am. J. Ophthalmol. 126:487-497, 1998.

7. Goel, M., Picciani, R.G., Lee, R.K., and Bhattacharya, S.K. Aqueous humor dynamics: a review. Open Ophthalmol. J. 4:52-59, 2010.

8. Schmier, J., Hulme-Lowe, C., and Covert, D. Adjunctive therapy patterns in glaucoma patients using prostaglandin analogs. Clin. Ophthalmol. 10:1097-1104, 2014.

9. Djafari, F., Lesk, M.R., Harasymowycz, P.J., Desjardins, D., and Lachaine, J. Determinants of adherence to glaucoma medical therapy in a long-term patient population. $J$. Glaucoma. 18:238-243, 2009.

10. Ung, C., Zhang, E., Alfaro, T., Murakami, Y., Zhang, M., Seider, M.I., Lin, S.C., and Singh, K. Glaucoma severity and medication adherence in a county hospital population. Ophthalmology. 120:1150-1157, 2013.

11. McCarty, C.A., Mukesh, B.N., Kitchner, T.E., Hubbard, W.C., Wilke, R.A., Burmester, J.K., and Patchett, R.B. Intraocular pressure response to medication in a clinical setting: the Marshfield Clinic Personalized Medicine Research Project. J. Glaucoma. 17:372-377, 2008.
12. Dietlein, T., Jordan, J., Dinslage, S., and Krieglstein, G. What do glaucoma specialists know about their patients? Graefes. Arch. Clin. Exp. Ophthalmol. 244:859-862, 2006.

13. Lee, A.J., Wang, J.J., Kifley, A., and Mitchell, P. Open-angle glaucoma and cardiovascular mortality: the Blue Mountains Eye Study. Ophthalmology. 113:1069-1076, 2006.

14. Wu, S.Y., Nemesure, B., Hennis, A., Schachat, A.P., Hyman, L., and Leske, M.C.; Barbados Eye Studies G. Openangle glaucoma and mortality: the Barbados Eye Studies. Arch. Ophthalmol. 126:365-370, 2008.

15. Han, J.A., Frishman, W.H., Wu Sun, S., Palmiero, P.M., and Petrillo, R. Cardiovascular and respiratory considerations with pharmacotherapy of glaucoma and ocular hypertension. Cardiol. Rev. 16:95-108, 2008.

16. Cracknell, K., and Grierson, I. Prostaglandin analogues in the anterior eye: their pressure lowering action and side effects. Exp. Eye Res. 88:786-791, 2009.

17. Alm, A., Grierson, I., and Shields, M.B. Side effects associated with prostaglandin analog therapy. Surv. Ophthalmol. 53 Suppl1:S93-S105, 2008.

18. Holló, G. The side effects of the prostaglandin analogues. Expert. Opin. Drug Saf. 6:45-52, 2007.

19. Schlotzer-Schrehardt, U., Zenkel, M., and Nusing, R.M. Expression and localization of FP and EP prostanoid receptor subtypes in human ocular tissues. Invest. Ophthalmol. Vis. Sci. 43:1475-1487, 2002.

20. Biswas, S., Bhattacherjee, P., and Paterson, C.A. Prostaglandin E2 receptor subtypes, EP1, EP2, EP3 and EP4 in human and mouse ocular tissues-a comparative immunohistochemical study. Prostaglandins. Leukot. Essent. Fatty Acids. 71:277-288, 2004.

21. Breyer, R.M., Bagdassarian, C.K., Myers, S.A., and Breyer, M.D. Prostanoid receptors: subtypes and signaling. Annu. Rev. Pharmacol. Toxicol. 41:661-690, 2001.

22. Narumiya, S., Sugimoto, Y., and Ushikubi, F. Prostanoid receptors: structures, properties, and functions. Physiol. Rev. 79:1193-1226, 1999.

23. Bito, L.Z. Comparison of the ocular hypotensive efficacy of eicosanoids and related compounds. Exp. Eye Res. 38: 181-194, 1984.

24. Gabelt, B.T., Hennes, E.A., Bendel, M.A., Constant, C.E., Okka, M., and Kaufman, P.L. Prostaglandin subtypeselective and non-selective IOP-lowering comparison in monkeys. J. Ocul. Pharmacol. Ther. 25:1-8, 2009.

25. Prasanna, G., Carreiro, S., Anderson, S., Gukasyan, H., Sartnurak, S., Younis, H., Gale, D., Xiang, C., Wells, P., Dinh, D., Almaden, C., Fortner, J., Toris, C., Niesman, M., Lafontaine, J., and Krauss, A. Effect of PF-04217329 a prodrug of a selective prostaglandin $\mathrm{EP}(2)$ agonist on intraocular pressure in preclinical models of glaucoma. Exp. Eye Res. 93:256-264, 2011.

26. Saeki, T., Ota, T., Aihara, M., and Araie, M. Effects of prostanoid EP agonists on mouse intraocular pressure. Invest. Ophthalmol. Vis. Sci. 50:2201-2208, 2009.

27. Kirihara, T., Taniguchi, T., Yamamura, K., Iwamura, R., Yoneda, K., Odani-Kawabata, N., Shimazaki, A., Matsugi, T., Shams, N., and Zhang, J.Z. Pharmacologic characterization of omidenepag isopropyl, a novel selective EP2 receptor agonist, as an ocular hypotensive agent. Invest. Ophthalmol. Vis. Sci. 59:145-153, 2018.

28. Ihekoromadu, N., Lu, F., Iwamura, R., Yoneda K., Kawabata-Odani, N., Shams, N.K. Safety and Efficacy of DE117, a Selective EP2 Agonist in a Phase 2a Study. Association for Research in Vision and Ophthalmology. Invest. Ophthalmol. Vis. Sci. 56:E-Abstract 5708, 2015. Available 
at: https://iovs.arvojournals.org/article.aspx ?articleid=2335 769\&resultClick=1 Accessed June 29, 2018.

29. Nilsson, S.F., Drecoll, E., Lutjen-Drecoll, E., Toris, C.B., Krauss, A.H., Kharlamb, A., Nieves, A., Guerra, T., and Woodward, D.F. The prostanoid EP2 receptor agonist butaprost increases uveoscleral outflow in the cynomolgus monkey. Invest. Ophthalmol. Vis. Sci. 47:4042-4049, 2006.

30. Toris, C.B., Coleman, R., Fan, S., Woodrooffe, A.J., Woodward, D.F. Identification of a highly efficacious, ultralong acting ocular hypotensive agent in non-human primates. Association for Research in Vision and Ophthalmology. Invest. Ophthalmol. Vis. Sci. 56:E-Abstract 4848, 2015. Available at: https://iovs.arvojournals.org/article.aspx?article id=2334830\&resultClick=1 Accessed June 29, 2018.

31. Lee, P.Y., Podos, S.M., Serle, J.B., Camras, C.B., and Severin, C.H. Intraocular pressure effects of multiple doses of drugs applied to glaucomatous monkey eyes. Arch. Ophthalmol. 105:249-252, 1987.

32. Toris, C.B., Zhan, G.L., Wang, Y.L., Zhao, J., McLaughlin, M.A., Camras, C.B., and Yablonski, M.E. Aqueous humor dynamics in monkeys with laser-induced glaucoma. J. Ocul. Pharmacol. Ther. 16:19-27, 2000.

33. Toris, C.B., McLaughlin, M.A., Dworak, D.P., Fan, S., Havens, S., Zhan, G.L., Horan, N., and Prasanna, G. Effects of Rho kinase inhibitors on intraocular pressure and aqueous humor dynamics in nonhuman primates and rabbits. $J$. Ocul. Pharmacol. Ther. 32:355-364, 2016.

34. Aihara, M., Lu, F., Kawata, H., Tanaka, Y., Yamamura, K., Iwamura, R., Yoneda, K., Odani, N., Shams, N. Pharmacokinetics, Safety and IOP lowering profiles of omidenepag isopropyl, a selective EP2 agonist in healthy Japanese and caucasian volunteers (Phase I Study). Association for Research in Vision and Ophthalmology. Invest. Ophthalmol. Vis. Sci. 58:E-Abstract 2104, 2017. Available at: https://iovs. arvojournals.org/article.aspx? articleid=2639785\&resultClick =1 Accessed June 29, 2018.

35. Erickson, K., Gonnering, R., Kaufman, P., and Dortzbach, $\mathrm{R}$. The cynomolgus monkey as a model for orbital research. III. effects on ocular physiology of lateral orbitotomy and isolation of the ciliary ganglion. Curr. Eye Res. 3:557-564, 1984.

36. Brubaker, R.F. The flow of aqueous humor in the human eye. Trans. Am. Ophthalmol. Soc. 80:391-474, 1982.

37. Yablonski, M.E., Cook, D.J., and Gray, J. A fluorophotometric study of the effect of argon laser trabeculoplasty on aqueous humor dynamics. Am. J. Ophthalmol. 99:579-582, 1985.

38. Mäepea, O., and Bill, A. Pressures in the juxtacanalicular tissue and schlemm's canal in monkeys. Exp. Eye Res. 54: 879-883, 1992.

39. Maepea, O., and Bill, A. The pressures in the episcleral veins, Schlemm's canal and the trabecular meshwork in monkeys: effects of changes in intraocular pressure. Exp. Eye Res. 49:645-663, 1989.

40. Toris, C.B., Zhan, G.L., Camras, C.B., and McLaughlin, M.A. Effects of travoprost on aqueous humor dynamics in monkeys. J. Glaucoma. 14:70-73, 2005.

41. Toris, C.B., and Pederson, J.E. Effect of intraocular pressure on uveoscleral outflow following cyclodialysis in the monkey eye. Invest. Ophthalmol. Vis. Sci. 26:1745-1749, 1985.

42. Bill, A. Conventional and uveo-scleral drainage of aqueous humour in the cynomolgus monkey (Macaca irus) at normal and high intraocular pressures. Exp. Eye Res. 5:45-54, 1966.
43. Bill, A. Further studies on the influence of the intraocular pressure on aqueous humor dynamics in cynomolgus monkeys. Invest. Ophthalmol. Vis. Sci. 6:364-372, 1967.

44. Toris, C.B., Gabelt, B.T., and Kaufman, P.L. Update on the mechanism of action of topical prostaglandins for intraocular pressure reduction. Surv. Ophthalmol. 53 Suppl1: S107-S120, 2008.

45. Toris, C.B., Yablonski, M.E., Wang, Y.L., and Hayashi, M. Prostaglandin A2 increases uveoscleral outflow and trabecular outflow facility in the cat. Exp. Eye Res. 61:649657, 1995.

46. Toris, C.B., Koepsell, S.A., Yablonski, M.E., and Camras, C.B. Aqueous humor dynamics in ocular hypertensive patients. J. Glaucoma. 11:253-258, 2002.

47. Toris, C.B. Pharmacotherapies for glaucoma. Curr. Mol. Med. 10:824-840, 2010.

48. Toris, C.B., Camras, C.B., and Yablonski, M.E. Acute versus chronic effects of brimonidine on aqueous humor dynamics in ocular hypertensive patients. Am. J. Ophthalmol. 128:8-14, 1999.

49. Isobe, T., Mizuno, K., Kaneko, Y., Ohta, M., Koide, T., and Tanabe, S. Effects of K-115, a rho-kinase inhibitor, on aqueous humor dynamics in rabbits. Curr. Eye Res. 39: 813-822, 2014.

50. Kiel, J.W., and Kopczynski, C.C. Effect of AR-13324 on episcleral venous pressure in Dutch belted rabbits. J. Ocul. Pharmacol. Ther. 31:146-151, 2015.

51. Taniguchi, T., Kirhara, T., Takahashi, M., Iwamura, R., Yoneda, K., Odani, N., Shimazaki, A., Ichikawa, M., Zhang, J-Z. Omidenepag isopropyl, a selective EP2 agonist, shows additive intraocular pressure (IOP)-lowering effects when used concomitantly with existing anti-glaucoma drugs in animal models. Association for Research in Vision and Ophthalmology. Invest. Ophthalmol. Vis. Sci. 58: E-Abstract 2105, 2017. Available at: https://iovs.arvojournals. org/article.aspx ?articleid=2639786\&resultClick=1 Accessed June 29, 2018.

52. Sugimoto, Y., and Narumiya, S. Prostaglandin E receptors. J. Biol. Chem. 282:11613-11617, 2007.

53. Coleman, R.A., Smith, W.L., and Narumiya, S. International Union of Pharmacology classification of prostanoid receptors: properties, distribution, and structure of the receptors and their subtypes. Pharmacol. Rev. 46:205-229, 1994.

54. Crider, J.Y., and Sharif, N.A. Functional pharmacological evidence for EP2 and EP4 prostanoid receptors in immortalized human trabecular meshwork and non-pigmented ciliary epithelial cells. J. Ocul. Pharmacol. Ther. 17:35-46, 2001.

55. Fujimoto, N., and Shichi, H. Effect of prostaglandins on cultured porcine iris sphincter muscle cells. J. Ocul. Pharmacol. Ther. 12:343-351, 1996.

56. Krauss, A.H., Wiederholt, M., Sturm, A., and Woodward, D.F. Prostaglandin effects on the contractility of bovine trabecular meshwork and ciliary muscle. Exp. Eye Res. 64: 447-453, 1997.

57. Kalouche, G., Beguier, F., Bakria, M., Melik-Parsadaniantz, S., Leriche, C., Debeir, T., Rostene, W., Baudouin, C., and Vige, X. Activation of prostaglandin FP and EP2 receptors differently modulates myofibroblast transition in a model of adult primary human trabecular meshwork cells. Invest. Ophthalmol. Vis. Sci. 57:1816-1825, 2016.

58. Yen, J., Kocieda, V., Jing, H., and Ganea, D. Prostaglandin E2 induces matrix metalloproteinase 9 expression in dendritic cells through two independent signaling pathways 
leading to activator protein 1 (AP-1) activation. J. Biol. Chem. 286:38913-38923, 2011.

59. Lee, J., Banu, S., Subbarao, T., Starzinski-Powitz, A., and Arosh, J. Selective inhibition of prostaglandin E2 receptors EP2 and EP4 inhibits invasion of human immortalized endometriotic epithelial and stromal cells through suppression of metalloproteinases. Mol. Cell. Endocrinol. 332: 306-313, 2011.

60. Gaasterland, D., and Kupfer, C. Experimental glaucoma in the rhesus monkey. Invest. Ophthalmol. 13:455-457, 1974.

61. Radius, R.L., and Pederson, J.E. Laser-induced primate glaucoma. II. Histopathology. Arch. Ophthalmol. 102:16931698, 1984.
Received: December 25, 2017

Accepted: April 23, 2018

Address correspondence to: Dr. Masahiro Fuwa $R \& D$ Division

Santen Pharmaceutical Co., Ltd. 8916-16 Takayama-cho Ikoma-shi Nara 630-0101

Japan

E-mail: masahiro.fuwa@santen.com 